\title{
Cardiopulmonary exercise testing in patients with non-small cell lung cancer: trust the $\dot{\mathrm{V}}_{2 \text { peak }}$ ?
}

\author{
Francis-Edouard Gravier ${ }^{1,2}$, Tristan Bonnevie ${ }^{1,2}$, Fairuz Boujibar ${ }^{3,4}$, Clément Médrinal $^{2,5}$, \\ Guillaume Prieur $^{2,5}$, Yann Combret ${ }^{5,6}$, Jean-François Muir ${ }^{1,2}$, Jean-Marc Baste ${ }^{3,4}$, David Debeaumont ${ }^{7}$, \\ Antoine Cuvelier ${ }^{2,8}$
}

${ }^{1}$ ADIR Association, Rouen University Hospital, Rouen, France; ${ }^{2}$ Normandy University UNIROUEN, UPRES EA 3830 , Haute Normandie Research and Biomedical Innovation, Rouen, France; ${ }^{3}$ Department of Thoracic Surgery, Rouen University Hospital, Rouen, France; ${ }^{4}$ Normandy University UNIROUEN, INSERM U1096, Haute Normandie Research and Biomedical Innovation, Rouen, France; ${ }^{5}$ Medico-surgical Intensive Care Unit, Jacques Monod Hospital, Le Havre, France; ${ }^{6}$ Institut de Recherche Expérimentale et Clinique (IREC), Pôle de Pneumologie, ORL and Dermatologie, Université Catholique de Louvain, Brussels 1200, Belgium; ${ }^{7}$ Department of Respiratory and Exercise Physiology and CIC-CRB 1404, Rouen University Hospital, Rouen, France; ${ }^{8}$ Pulmonary, Thoracic Oncology and Respiratory Intensive Care Department, Rouen University Hospital, Rouen, France

Contributions: (I) Conception and design: FE Gravier, T Bonnevie, D Debeaumont; (II) Administrative support: JF Muir, JM Baste, A Cuvelier; (III) Provision of study materials or patients: D Debeaumont, JF Muir, JM Baste; (IV) Collection and assembly of data: FE Gravier, T Bonnevie, F Boujibar, D Debeaumont; (V) Data analysis and interpretation: FE Gravier, T Bonnevie, C Médrinal; (VI) Manuscript writing: All authors; (VII) Final approval of manuscript: All authors.

Correspondence to: Francis-Edouard Gravier. ADIR Association, 147 avenue du Maréchal Juin 76230 Bois-Guillaume, France.

Email: f.gravier@adir-hautenormandie.com.

Background: Maximal oxygen consumption $\left(\dot{\mathrm{VO}_{2 \max }}\right)$ is the most frequently used variable to determine postoperative risk in patients with non-small cell lung cancer (NSCLC), however patients frequently cannot provide the necessary maximum effort to ensure the validity of the $\dot{\mathrm{V}} \mathrm{O}_{2}$ measurements. The aim of this observational study was to assess exercise-limiting factors and the rate of achievement of the currently recommended maximality criteria in patients with NSCLC who had been routinely referred for cardiopulmonary exercise testing (CPET) to assess their postoperative risk.

Methods: Patient data, including peak exercise variables and markers used to designate the exercise test as maximal, were retrospectively analysed from 203 preoperative CPET assessments that were performed at Rouen University Hospital from January 2014 until July 2019.

Results: Ventilatory limitation was the most common physiological cause of exercise cessation. A total of 62 patients (or $30.5 \%$ ) achieved either one, or no, markers of maximality. The mean duration of the incremental phase (after the 3-minute warm-up) was $5.1 \pm 2$ minutes.

Conclusions: About $30 \%$ of the patients in this study did not generate maximum effort during CPET. As a result, it is likely that their $\dot{\mathrm{V}}{ }_{2 \text { peak }}$ was underestimated and that their post-operative risk was overestimated. It is therefore important to incorporate strategies to verify $\dot{\mathrm{V}} \mathrm{O}_{\text {2peak }}$ results for patients with values close to the risk threshold.

Keywords: Cardiopulmonary exercise testing (CPET); non-small cell lung cancer (NSCLC); lung resection; preoperative assessment; oxygen consumption

Submitted Mar 30, 2020. Accepted for publication Aug 14, 2020.

doi: $10.21037 /$ jtd-20-1528

View this article at: http://dx.doi.org/10.21037/jtd-20-1528 


\section{Introduction}

Lung cancer is now the most common form of cancer diagnosed and the leading cause of cancer death worldwide (1). Remarkable advances have been made in recent years regarding diagnosis and therapy (2). Lung resection is the primary curative treatment for the early stages of non-small cell lung cancer (NSCLC) (3). Resection may also be carried out in the more advanced stages, as part of a broader therapeutic strategy (4).

Cardiopulmonary exercise testing (CPET) is currently recommended by both the European Respiratory Society and the American Thoracic Society as part of the preoperative evaluation of patients with NSCLC who have respiratory comorbidities and/or functional limitations $(5,6)$. CPET is a comprehensive physiological testing procedure that evaluates cardiovascular, respiratory and metabolic variables, as well as perceived exertion. The most commonly used method for CPET is the incremental test, which involves a gradual increase in load. The incremental test is standardized and has been shown to be reliable (7).

Maximum oxygen consumption $\left(\dot{\mathrm{V}} \mathrm{O}_{2 \max }\right.$ ) has been described as a potent predictor of postoperative complications in patients with NSCLC (8) and thus is a key variable measured by CPET. The risk of complications is considered to be low for values above $20 \mathrm{~mL} / \mathrm{kg} / \mathrm{min}$, moderate for values between 10 and $20 \mathrm{~mL} / \mathrm{kg} / \mathrm{min}$ and high for values below $10 \mathrm{~mL} / \mathrm{kg} / \mathrm{min}(5,6)$. The $\dot{\mathrm{V}} \mathrm{O}_{2 \max }$ results are therefore used in the surgical decision-making process and may be used to determine if preoperative rehabilitation is necessary.

However, it has recently been suggested that the use of a single incremental test for the evaluation of $\dot{\mathrm{V}} \mathrm{O}_{2 \text { max }}$ may lead to an underestimation of $\dot{\mathrm{V}}{ }_{2 \text { max }}$ (9). Although the measurement of $\dot{\mathrm{V}}_{2 \max }$ is highly accurate in subjects who are experienced in performing exercise to volitional exhaustion, other populations, such as patients, inexperienced subjects or less motivated individuals, may stop exercising before their $\dot{\mathrm{V}}{ }_{2 \max }$ is reached. For this reason, the $\dot{\mathrm{V}} \mathrm{O}_{2 \text { peak }}$, which is the highest value reached during a clinically limited incremental CPET, is often used instead as a surrogate of their real $\dot{\mathrm{V}}_{2 \max }$. However, patients with low $\dot{\mathrm{V}} \mathrm{O}_{2 \text { peak }}$ values may therefore be denied surgery, because of overestimation of their risk.

We hypothesized that a significant proportion of patients referred for physiological evaluation do not provide maximum effort. The aim of this study was to describe peak exercise variables and the achievement of markers used to consider CPET as maximal in patients with NSCLC. Secondly duration of the incremental ramp and load increments were analysed. The following article is presented in accordance with the "Strengthening the Reporting of Observational Studies in Epidemiology (STROBE)" reporting checklist (10) (Available at http:// dx.doi.org/10.21037/jtd-20-1528).

\section{Methods}

\section{Patients and design}

Patients with a diagnosis or suspicion of NSCLC and impaired pulmonary function or comorbidities, consecutively referred between January 2014 and July 2019, for CPET to determine surgical risks at the Rouen University Hospital respiratory and exercise physiology department, were retrospectively included. Incomplete records and tests without gas exchange analysis were not included. Only the first-ever CPET on a cycle-ergometer was considered to exclude learning effect. The study was conducted in accordance with the Declaration of Helsinki (as revised in 2013). The study was approved by institutional Rouen University Hospital ethics committee ( $\left.{ }^{\circ} \mathrm{E} 2019-47\right)$ and individual consent for this retrospective analysis was waived.

\section{Data extraction}

The following data were extracted: age, sex, height, weight, body mass index (BMI), pulmonary function, maximal capacity variables at the end of CPET, smoking status (never/former/current), exposure to tobacco (expressed as $\mathrm{pack} / \mathrm{years}$; $1 \mathrm{pack} / \mathrm{year}=$ one pack per day for one year), tumour histology and stage on the 7th Tumor Node Metastasis (TNM) classification (11).

\section{Assessments}

\section{Pulmonary function}

Pulmonary function tests (PFT) were carried out according to the American Thoracic Society and the European Respiratory Society guidelines using plethysmography (Masterscreen, Jaeger, Wittsburg, Germany). Values were expressed as percentages of established theoretical values for European populations (12). Predictive postoperative (PPO) forced expiratory volume in 1 second (FEV1) and diffusing capacity of the lung for carbon monoxide (DLCO) were calculated according to the equations recommended by the ERS/ESTS guidelines (5). 


\section{CPET}

CPET was performed on an electromagnetic ergometer (Ergoselect 200, Ergoline, Bitz, Germany) using a standardised, incremental protocol (7). Following a threeminute warm-up, load was increased by a constant amount each minute until exhaustion. The selected increment was individualized between 5 to 15 watts/min according to the predicted maximal capacity and estimated physical level during the consultation preceding the CPET). Heart rate (HR) was continuously monitored with a 12-lead electrocardiogram (Ergocard, Medisoft, Louvain Belgium). A face mask (Hans Rudolph, Inc., Kansas City, MO, USA), pneumotach and gas analyser (Ergocard, Medisoft, Louvain, Belgium) were used to measure breath-by-breath oxygen consumption $\left(\dot{\mathrm{V}}_{2}\right)$ and carbon dioxide production $\left(\dot{\mathrm{V} C O}_{2}\right)$. Peak oxygen consumption $\left(\dot{\mathrm{V}}_{2 \text { peak }}\right)$ was the highest $\dot{\mathrm{V}} \mathrm{O}_{2}$ value during an average of three to five breath during the exercise ramp. The predicted maximal work rate $\left(W_{\max }\right)$ and $\dot{\mathrm{V}} \mathrm{O}_{2 \max }$ was derived from the equations reported by Wasserman et al. (13). Ventilatory threshold (VT) was manually determined as the average of the results obtained using the first break in $\mathrm{VE}, \mathrm{V}$-slope and ventilatory equivalents methods (7).

\section{Markers used to designate the exercise test as maximal (7)}

The end criteria for reaching maximal oxygen uptake were based on American Thoracic Society/American College of Chest Physicians' recommendations were:

(I) The patient achieved their predicted maximal $\dot{\mathrm{VO}}_{2}$ ( $\geq 85 \%$ predicted) and/or a plateau was observed;

(II) Their predicted maximal work rate $\left(\mathrm{W}_{\max }\right)$ was achieved;

Predicted maximal heart rate (HR) was achieved; with $\mathrm{HR}_{\text {max }}$ predicted $=208-0.7 \times$ age $(14)$;

Evidence of ventilatory limitation i.e. ventilatory reserve $(\mathrm{VR})>85 \%$ with $\mathrm{VR}=\dot{\mathrm{VEmax}} / \mathrm{MVV} \times 100$ and maximal voluntary ventilation $(\mathrm{MVV})=\mathrm{FEV} 1 \times 35$;

The patient overcame a respiratory exchange ratio (RER) value of 1.15 ;

Patient exhaustion/Borg scale rating of $9-10$ on a 0 to 10 scale.

\section{Statistical analysis}

Categorial data were expressed as numbers (percentages). Continuous data were expressed as means $( \pm$ standard deviation) or medians $\left(25^{\text {th }}-75^{\text {th }}\right.$ percentile) according to the data distribution. Normality was assessed using the D'Agostino \& Pearson omnibus normality test. Correlation between the duration of the incremental phase of CPET and the number of markers achieved for the determination of a maximal exercise test were evaluated with a Spearman correlation test. A one-way analysis of variance with a Bonferroni multiple comparison test was used to compare the between-patient duration of the CPET incremental phase as assessed with minute-increments of 15, 10 or 5 watts. A P value $<0.05$ was considered statistically significant. GraphPad Prism 5.03 and R 3.6.1 software was used for all analyses.

\section{Results}

\section{Patients}

Over the data collection period, 217 patients who were either diagnosed, or being diagnosed, with NSCLC were referred for CPET to evaluate their risks for surgery although only 203 patients' CPET results were analysed for this study. Table 1 summarizes patient characteristics, and comorbidities-medications are detailed in Table S1. Data from 14 patients from the original 217 were not included. Two patients were found to have cardiac disorders at the pre-CPET medical consultation which contradicted using the test. A further 10 patients did not undergo gas exchange analysis: 7 were receiving oxygen therapy, 2 could not have the analysis due to a lack of a tracheostomyadapted equipment interfaces and 1 patient's mask had to be removed during the CPET. Finally, another 2 patients had to be excluded for reasons of consistency because their CPET was carried out on a treadmill and not cycloergometer (see flow chart in Figure 1).

\section{Peak exercise variables}

The results showed a clear limitation of aerobic capacity in this population as demonstrated by a $\dot{\mathrm{V}} \mathrm{O}_{\text {2peak }}$ below $85 \%$ of the predicted $\dot{\mathrm{V}}_{2 \max }$, for $86.2 \%$ of the patients included. The whole peak exercise variables are reported in Table 2.

\section{Physiological limitations}

First, ventilatory limitation was the most frequent physiological cause of effort limitation. One hundred and four patients presented mechanical ventilatory limitation 
Table 1 Patient characteristics $(\mathrm{n}=203)$

\begin{tabular}{|c|c|}
\hline Variable (units) & Outcome \\
\hline Female, n (\%) & $55(27.1)$ \\
\hline Age (years), median (IQR) & $64(59-69)$ \\
\hline Height (cm), median (IQR) & $170(164-175)$ \\
\hline Weight (kg), median (IQR) & $71.0(59.0-89.0)$ \\
\hline BMI $\left(\mathrm{kg} / \mathrm{m}^{2}\right)$, median (IQR) & $25.5(21.2-30.7)$ \\
\hline FEV1 (liter), median (IQR) & $1.8(1.4-2.2)$ \\
\hline FEV1 $1_{\mathrm{PPO}}$ (liter), median (IQR) & $1.4(1.2-1.8)$ \\
\hline FEV1 (\% pred.), median (IQR) & $66.0(54.0-80.0)$ \\
\hline FEV1 $1_{\mathrm{PPO}}(\%$ pred.), median (IQR) & $52.0(43.5-60.5)$ \\
\hline FVC (liter), median (IQR) & $3.0(2.5-3.6)$ \\
\hline FVC (\% pred.), mean \pm SD & $87.5 \pm 17.3$ \\
\hline FEV1/FVC, mean \pm SD & $61.6 \pm 12.2$ \\
\hline FEV1/FVC <70, n (\%) & $144(70.9)$ \\
\hline $\mathrm{RV} / \mathrm{TLC}$, mean $\pm \mathrm{SD}$ & $51.4 \pm 10.6$ \\
\hline DLCO (\%Theo), median (IQR) & $57.0(47.0-70.0)$ \\
\hline $\mathrm{DLCO}_{\mathrm{PPO}}(\%$ Theo), median (IQR) & $45.0(39.0-56.0)$ \\
\hline \multicolumn{2}{|l|}{ Tobacco } \\
\hline Non-smoker, n (\%) & $4(2.0)$ \\
\hline Smoker, n (\%) & $62(30.5)$ \\
\hline Former, n (\%) & $137(67.5)$ \\
\hline Exposure (pack-years), median (IQR) & $45.0(34.5-60.0)$ \\
\hline \multicolumn{2}{|l|}{ NSCLC stage, n (\%) } \\
\hline 0 & $4(2.0)$ \\
\hline la & $35(17.2)$ \\
\hline $\mathrm{lb}$ & $28(13.8)$ \\
\hline Ila & $9(4.4)$ \\
\hline $\mathrm{Ilb}$ & $11(5.4)$ \\
\hline Illa & $28(13.8)$ \\
\hline IIllb & $9(4.4)$ \\
\hline IV & $18(8.9)$ \\
\hline NS & $61(30.0)$ \\
\hline \multicolumn{2}{|l|}{ Histology, n (\%) } \\
\hline Large cell carcinoma & $21(10.3)$ \\
\hline Squamous carcinoma & $50(24.6)$ \\
\hline Adenocarcinoma & $78(38.4)$ \\
\hline
\end{tabular}

Table 1 (continued)
Table 1 (continued)

\begin{tabular}{lc}
\hline Variable (units) & Outcome \\
\hline Other postoperative diagnosis & $8(3.9)$ \\
Large cell neuroendocrine carcinoma & $2(1.0)$ \\
NS & $44(21.7)$ \\
\hline
\end{tabular}

NS, not specified; BMI, body-mass index; FEV1, forced expiratory volume in 1 second; FVC, forced vital capacity; RV, residual volume; TLC, total lung capacity; DLCO, diffusing capacity of the lung for carbon monoxide; $\dot{V}_{2 p e a k}$, peak of oxygen consumption; $W_{\text {peak, }}$ peak work rate; $\dot{\mathrm{V}} / \mathrm{V}^{\mathrm{V}} \mathrm{CO}_{2}$ slope, linear regression of the ratio between the increase in minute ventilation $(\dot{\mathrm{V}} \mathrm{E})$ and the expired carbon dioxide flow $\left(\dot{\mathrm{V}} \mathrm{CO}_{2}\right)$; NSCLC, non-small cell lung cancer.

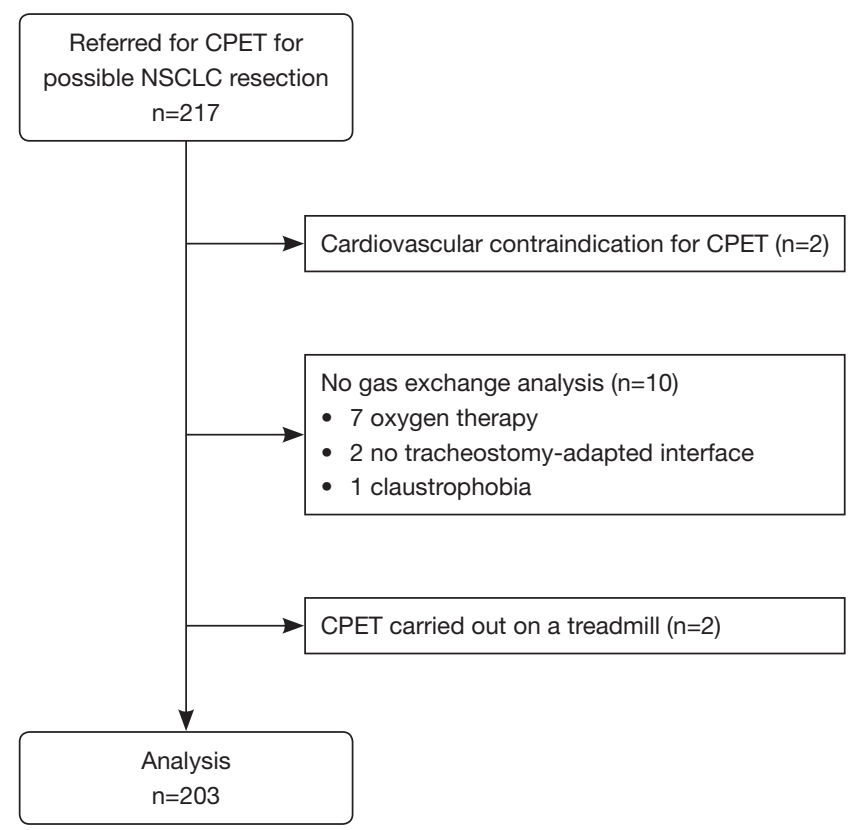

Figure 1 Flow chart of patients included in the study from January 2014 to July 2019. CPET, cardiopulmonary exercise testing; NSCLC, non-small cell lung cancer.

limitations with exhaustion of their VR. In addition, 37 patients presented gas-exchange impairment with desaturation $\geq 4 \%$ during the CPET. Most of them (34/37) were associated with an exhaustion of the VR, or deficit of diffusion observed on the PFT (3/37).

This was followed by peripheral muscle deconditioning, diagnosed on the basis of the conjunction of different factors such as an early ventilatory threshold, peripheral fatigue, poor performance in terms of power reached, 
Table 2 CPET outcomes ( $\mathrm{n}=203)$

\begin{tabular}{|c|c|}
\hline Variable (units) & Outcome \\
\hline$\dot{\mathrm{V}}_{2 \text { peak }}(\mathrm{mL} / \mathrm{kg} / \mathrm{min})$, median $(\mathrm{IQR})$ & $14.6(12.2-17.0)$ \\
\hline$\dot{\mathrm{V}} \mathrm{O}_{2 \text { peak }}(\%$ pred.), median (IQR) & $63.0(54.0-74.0)$ \\
\hline$\dot{\mathrm{VO}}_{2 \mathrm{VT} /} \dot{\mathrm{VO}}_{2 \max }(\mathrm{n}=191)$, median (IQR) & $46.0(39.0-53.0)$ \\
\hline$W_{\text {peak }}$ (Watts), median (IQR) & $80.0(60.0-100.0)$ \\
\hline$W_{\text {peak }}(\%$ pred.), median (IQR) & $66.0(52.0-79.0)$ \\
\hline$W_{\text {peak }} / \mathrm{kg}$, median (IQR) & $1.1(0.9-1.4)$ \\
\hline VEE/VCO 2 slope, median (IQR) & $36.0(31.6-41.0)$ \\
\hline $\mathrm{HR}_{\max }(\%$ pred.), median (IQR) & $81.0(72.0-90.0)$ \\
\hline$\dot{V}_{\max }(\% \mathrm{MVV}$ pred.), median (IQR) & $85.0(70.0-100.0)$ \\
\hline $\begin{array}{l}\text { Dyspnoea (Borg scale/10) }(n=148) \text {, } \\
\text { median (IQR) }\end{array}$ & $5.0(3.0-6.0)$ \\
\hline $\begin{array}{l}\text { Leg fatigue (Borg scale/10) }(\mathrm{n}=148) \text {, } \\
\text { median (IQR) }\end{array}$ & $4.0(2.8-7.0)$ \\
\hline \multicolumn{2}{|c|}{ 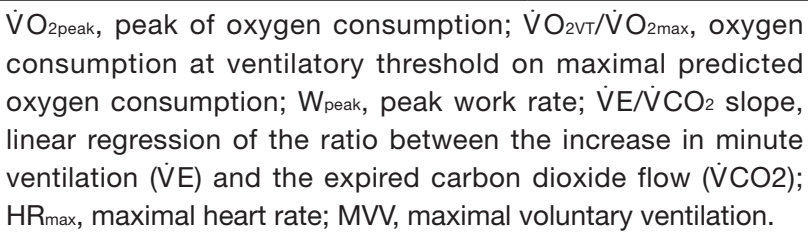 } \\
\hline
\end{tabular}

muscle wasting, sedentary behaviour. Ventilatory threshold (VT) could not be measured for 12 patients and the ratio $\dot{\mathrm{V}} \mathrm{O}_{2}$ at $\mathrm{VT} / \dot{\mathrm{VO}}_{2 \max }$ predicted was below $40 \%$ for 49 patients. This reflects a limitation in $\mathrm{O}_{2}$ supply to the tissues, compatible in part with deconditioning. Moreover, the median power/body-weight ratio was 1.1 watts/kilogram at peak exercise, which reflects poor performance in terms of power developed. Muscle deconditioning was rarely an isolated cause of limitation because it stemmed from health history.

Finally, cardiovascular function contributed to exercise limitation. Forty-two patients had peripheral arterial disease and 25 diagnosed heart disease (10 overlaps), which impacted their exercise performance. Although 35 patients were on beta-blocker, only 9 cases of chronotropic incompetence were highlighted as the main limiting factor. Fifteen patients presented an alteration of the ECG (sus/ sub-ST, repolarization disorder, ventricular extrasystole) of which 7 required the early cessation of the effort, the others having occurred at near-maximum effort. Two cases of arterial hypertension $(\geq 250 / 120 \mathrm{mmHg}$ ) necessitated to stop the CPET, one prematurely, and one at near-maximum effort. A pathological kinetics of the $\mathrm{O}_{2}$ pulse were noted
Table 3 Markers of maximality $(n=203)$

\begin{tabular}{|c|c|}
\hline Variable & n (\%) \\
\hline \multicolumn{2}{|c|}{$\begin{array}{l}\text { Markers used for the determination of a "maximal" exercise } \\
\text { test (7) }\end{array}$} \\
\hline $\begin{array}{l}\text { Predicted } \dot{\mathrm{V}}_{2 \text { peak }} \text { achieved ( } \geq 85 \% \dot{\mathrm{VO}}_{2 \max } \text { pred.) } \\
\text { and/or plateau observed }\end{array}$ & $66(32.5)$ \\
\hline Predicted $\mathrm{W}_{\max }$ achieved ( $\geq 90 \%$ pred.) & $22(10.8)$ \\
\hline Predicted $\mathrm{HR}_{\max }$ achieved ( $\geq 90 \%$ pred.) & $51(25.1)$ \\
\hline VR $>85 \%$ & $104(51.2)$ \\
\hline RER $>1.15$ & $160(78.8)$ \\
\hline Borg score $\geq 9 / 10(n=148)$ & $17(11.4)$ \\
\hline \multicolumn{2}{|l|}{ Number of markers achieved, $\mathrm{n}(\%)$} \\
\hline $\mathrm{N}=0$ & $18(8.9)$ \\
\hline $\mathrm{N}=1$ & $61(30.0)$ \\
\hline $\mathrm{N}=2$ & $72(35.5)$ \\
\hline $\mathrm{N} \geq 3$ & $52(25.6)$ \\
\hline \multicolumn{2}{|l|}{ Other markers, n (\%) } \\
\hline $\mathrm{O}_{2}$ pulse at $\dot{\mathrm{V}} \mathrm{O}_{2 \text { peak }}>80 \%$ pred. & $102(50.2)$ \\
\hline $\mathrm{pH}<7.30$ or lactatemia $>8 \mathrm{mmol} / \mathrm{L}(\mathrm{n}=85)$ & $12 / 85(14.1)$ \\
\hline Decrease in $\mathrm{SpO}_{2} \geq 4 \%$ & $37(18.2)$ \\
\hline \multicolumn{2}{|c|}{$\begin{array}{l}\text { Data are expressed as } \mathrm{n}(\%) \text {. } \mathrm{V}_{2 \text { peak, }} \text { peak of oxygen } \\
\text { consumption; Wmax, maximal work rate; HRmax, maximal heart } \\
\text { rate; } \mathrm{VR} \text {, ventilatory reserve; RER, respiratory exchange ratio; } \mathrm{O}_{2} \\
\text { pulse, } \dot{\mathrm{OO}}_{2} / \mathrm{HR} \text {. }\end{array}$} \\
\hline
\end{tabular}

in 4 patients without diagnosed cardiac comorbidity, suggesting an unknown onset heart failure.

\section{Maximality criteria}

Using the strict marker of achievement of a $\dot{\mathrm{VO}}_{2}$ plateau to designate maximality, only 49 patients (24\%) achieved their "real" $\dot{\mathrm{V}} \mathrm{O}_{2 \max }$, the values reached by the other patients are therefore considered as $\dot{\mathrm{VO}}_{2 \text { peak }}$.

The analysis of maximality markers showed that tests were not performed to a real sustained effort for all patients. The median number of markers achieved for the determination of a maximal exercise test was 2 (range, 1-3) (Table 3, Figure 2). Although the RER was $>1.15$ in $78.8 \%$ of patients the other markers were less frequently achieved, in particular only around one-third of patients achieved a $\dot{\mathrm{V}} \mathrm{O}_{2 \text { peak }}>84 \%$ of the $\dot{\mathrm{V}} \mathrm{O}_{2 \text { max }}$ predicted and/or a $\dot{\mathrm{V}}{ }_{2}$ plateau, and only around one-quarter achieved the predicted $\mathrm{HR}_{\max }$. 


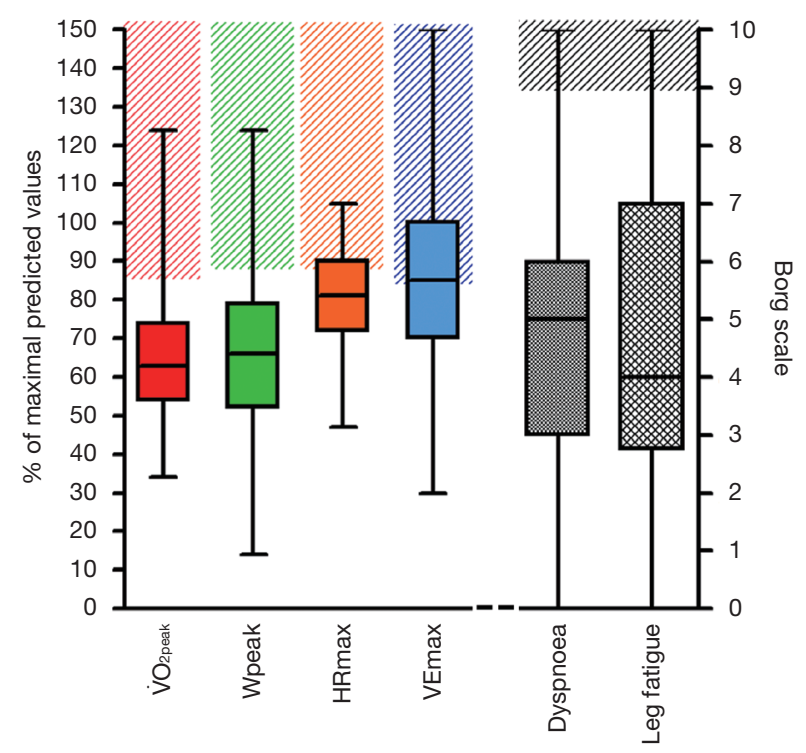

Figure 2 Percentage of maximal predicted values expressed as medians (25th-75th percentile) and ranges for peak oxygen consumption $\left(\dot{\mathrm{VO}}_{2 \text { peak }}\right)$ in red, peak work rate $\left(\mathrm{W}_{\text {peak }}\right)$ in green, maximal heart rate $\left(\mathrm{HR}_{\max }\right)$ in orange, maximal ventilation minute $\left(\mathrm{VE}_{\max }\right)$ in blue, dyspnoea and leg fatigue in grey. Stripes indicate achievement of maximality for the criterion (7).

Few patients achieved a high Borg scale rating for dyspnoea.

A total of 79 patients presented only one or no maximality criterion. Taking into account the 9 cases of chronotropic incompetence as well as the 8 cases of premature cessation for an adverse cardiovascular event, then 62 patients (or $30.5 \%$ ) were likely to have provided poor effort.

\section{Incremental protocols used}

The incremental protocols were set at 5, 10 or 15 watts per minute, according to the predicted maximal capacity and estimated physical level to theoretically last 8 to 12 minutes. The median load during the three minutes warm-up was 20 [10-30] watts, and the median load increment was 10 [10-15] watts per minute. The mean duration of the incremental phase (after warm-up) was $5.1 \pm 2.0$ minutes. A significant, positive correlation was found between the duration of the incremental phase of the CPET and the number of maximality markers achieved: $r=0.41, \mathrm{P}<0.0001$.

We compared the results obtained by patients who benefited from the three different load increments proposed. The mean duration of the incremental phase was significantly different between the three incremental load protocols $(4.3 \pm 1.7,5.7 \pm 2.0$, and $5.1 \pm 2.6$ min for 15,10 and $5 \mathrm{~W} / \mathrm{min}$ respectively, overall $\mathrm{P}<0.0001$ ), and was mainly driven by a significant difference between 15 and $10 \mathrm{~W} / \mathrm{min}$ increments $(\mathrm{P}<0.001)$ (Table 4).

\section{Discussion}

\section{Limitation of exercise capacity}

As expected, ventilatory factors were the main limitation of exercise capacity in this cohort of patients with NSCLC. More than $50 \%$ of the patients used over $85 \%$ of their VR, and $18 \%$ presented gas-exchange impairment. However, the definition of VR is debatable as some authors consider that patients begin to use their VR when ventilation exceeds $80 \%$ or even $70 \%$ of the predicted MVV $(15,16)$. Using these cut-offs, the rate of patients finishing the CPET with a reduced ventilatory reserve in the present study would be $(125 / 203) 62 \%$ or $(151 / 203) 74 \%$ respectively. It is important to note that many formulae have been proposed for the estimation of MVV based on the FEV1, although its validity is debatable, this indirect measure is widely used in clinical practice (17). Paradoxically, only a very small proportion of the patients achieved almost maximal or maximal rating dyspnoea. The median Borg rating for dyspnoea was 5 , which is defined as "severe" but is far from a score of 9 or 10, which are defined as "almost maximal or maximal". This is likely due to the difficulty of rating dyspnoea or the perception of effort on a scale by patients who are not used to physical activity. However these results are similar to peak exercise dyspnoea ratings reported in other cohort of patients with chronic obstructive pulmonary disease (18). This preponderant ventilation limitation could explain a very early cessation of effort without maximum cardiological or muscular solicitation.

The second limitation of exercise capacity demonstrated by CPET was the effect of deconditioning. Poor patient performance was associated with a rapidly reached inability to continue pedalling and an abnormally early ventilatory threshold. This was unsurprising given the sedentary lifestyle reported by the vast majority of patients during the pre-CPET consultation, and is consistent with other reports in the literature (19).

Cardiovascular comorbidities were the third limitation of exercise capacity, as described in the results. To go further, we noted that few patients achieved their predicted 
Table 4 Comparison of CPET between patients assessed with an increment per minute of 15,10 or 5 watts

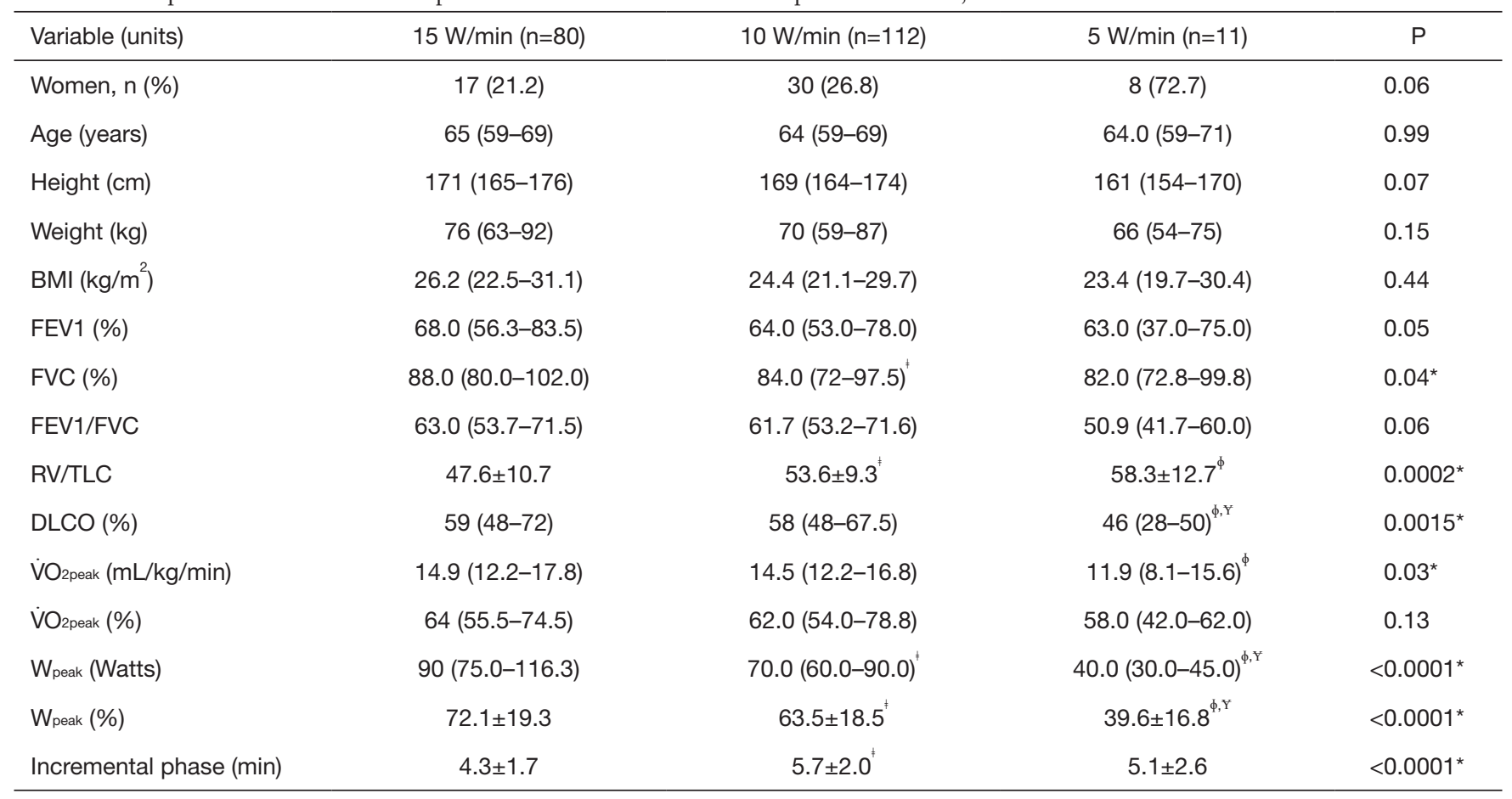

Values expressed as medians (IQR) or means \pm SD according to distribution; Chi-square test was used for contingency comparison; Kruskal Wallis test or a One-way analysis of variance with Dunn's or Bonferroni post-hoc test respectively were used according to distribution. ${ }^{*}$ Overall $\mathrm{P}<0.05 ;^{\ddagger}<0.05$ between 15 and $10 \mathrm{~W} / \mathrm{min} ;{ }^{\phi}<0.05$ between 15 and $5 \mathrm{~W} / \mathrm{min} ;{ }^{Y}<0.05$ between 10 and $5 \mathrm{~W} / \mathrm{min}$. CPET, cardiopulmonary exercise testing; BMI, body-mass index; FEV1, forced expiratory volume in 1 second; FVC, forced vital capacity; RV, residual volume; TLC, total lung capacity; DLCO, diffusing capacity of the lung for carbon monoxide; $\dot{V}_{2 p e a k}$, peak of oxygen consumption; Weak, peak work rate.

$\mathrm{HR}_{\max }$. This can simply means poor effort, but patients with lung hyperinflation have been shown to have poor cardiovascular responses during symptom-limited cycling exercise (20). It is also noteworthy that some patients in the present study were being treated with beta-blockers and experienced bradycardia during the exercise test. The $\mathrm{O}_{2}$ pulse at the $\dot{\mathrm{V}} \mathrm{O}_{2 \text { peak }}$ was less than $80 \%$ of the predicted value in almost half of the patients. A low $\mathrm{O}_{2}$-pulse suggests a lack of skeletal muscle oxygen extraction; this can indicate either peripheral deconditioning or, in some patients with cardiovascular comorbidities, a limitation of stroke volume (7).

\section{Risk of under-estimation of cardio-respiratory fitness}

As mentioned in the introduction, there may be various physical or mental reasons why patients are either unable or unwilling to achieve maximal effort e.g., osteoarthritis, arteriopathy, anxiety, kinesiophobia or a lack of motivation.
A previous study reported that individuals with NSCLC engage in less physical activity, are weaker and more depressed than healthy individuals (21). As a result of the difficulties in measuring maximal effort in these patients, several objective physiological criteria are measured along with $\dot{\mathrm{V}} \mathrm{O}_{2 \text { peak }}$ (as a surrogate for $\dot{\mathrm{V}} \mathrm{O}_{2 \text { max }}$ ) to determine the level of patient effort generated (7).

Plateauing of $\dot{\mathrm{VO}}_{2}$ at the end of the CPET is considered as an unambiguous sign of maximum oxygen uptake (9). This occurred in 49 (24\%) in the present study. It has also been suggested that an RER value $>1.15$ is associated with a maximal effort. Unfortunately, there is currently no single agreed value that defines what RER value constitutes maximal effort $(7,9)$. Therefore, in order to increase the certainty that maximal effort had been achieved, we considered that a CPET result could only be considered as indicative of maximal effort if at least two markers had been achieved. Based on this definition and taking into account adverse events, about $30 \%$ of the patients in this study did 
not achieve a physiologically maximal CPET.

Another factor potentially related to the underestimation of $\dot{\mathrm{V}}{ }_{2 \max }$ was the duration of the test. The mean duration of the incremental phase in the present cohort was $5.1 \pm$ 2.0 minutes. Moreover, as expected there was a positive correlation between the duration of the incremental exercise and the number of maximality criteria achieved. According to a previous study, cycle ergometer incremental exercise of less than 7 minutes can lead to an underestimation of cardiorespiratory fitness measured by $\dot{\mathrm{VO}}_{2 \max }$ (22).

As a result, it is reasonable to suggest that the $\dot{\mathrm{VO}}_{2 \text { peak }}$ results were lower than the value of the $\dot{\mathrm{VO}}_{2 \max }$. Care must therefore be taken in the use of $\dot{\mathrm{V}} \mathrm{O}_{\text {peak }}$ to determine the risk of post-operative complications in patients with NSCLC, particularly if the $\dot{\mathrm{V}} \mathrm{O}_{\text {2peak }}$ values are close to the thresholds of risk determined by the decisional algorithms $(5,6)$.

\section{Strategies to reduce the risk of underestimation}

\section{Low-intensity incremental protocols to increase the} duration of the CPET

As indicated above, strategies that could be used to reduce the risk of underestimation of $\dot{\mathrm{V}} \mathrm{O}_{2 \max }$ include increasing the duration of the incremental exercise. Current guidelines suggest that CPET should last for between 8 and 12 minutes (7). This guidance, however, is based on a 1983 study of 5 healthy subjects (23). More recent data has suggested that a minimum of 7 minutes and a maximum of 26 minutes of incremental effort on a cyclo-ergometer is more appropriate in order for patients to achieve maximal effort (22). We would therefore suggest that smaller load increments should be used to increase the duration of the exercise. In clinical terms, increments of 5 to 10 watts per minute would seem to be sufficient to obtain a suitable ramp for the vast majority of patients with NSCLC referred for CPET to determine their risk-benefit ratio ahead of surgery. This suggestion is supported by secondary analysis from this study which indicated that patients who underwent CPET with increments of 15 watts, rather than 10 watts, per minute did reach higher levels of $\dot{\mathrm{V}} \mathrm{O}_{2 \text { peak }}$ despite the higher work rate (Table 4). We believe that this was due to the significantly shorter duration of the incremental phase: $4.3 \pm 1.7$ minutes for the 15 -watt/min group, versus $5.7 \pm$ 2.0 minutes for the 10 -watt/min group. This duration may not have allowed adequate physiological adaptation in this cohort of older individuals with respiratory comorbidities and reduced $\dot{\mathrm{V}} \mathrm{O}_{2}$ kinetics $(24,25)$. Furthermore, less than $10 \%$ of patients exceeded a power of 120 watts and so the risk of prolonging the effort disproportionately with increments of 5 to 10 watts is very low, since the maximal expected power for a CPET with an increment of 15 watts per minute is about 150 watts. In clinical practice it is likely that patients who are able to reach this level of power would already have been identified as having a low postoperative risk during pre-CPET preliminary tests such as stair climbing or the shuttle test and so would not require CPET (6).

\section{Validation $\dot{\mathbf{V}} \mathbf{O}_{\text {2peak }}$ through a second evaluation}

Jones et al. recently have questioned the reliability of the measurement of $\dot{\mathrm{V}} \mathrm{O}_{2 \text { peak }}$ and suggested that a more appropriate strategy would be to validate the patient's $\dot{\mathrm{V}}{ }_{2 \max }$ through the addition of a second supra-maximal constant-load test (9). This method is physiologically robust and has already been validated for several pathologies (26). However, it is difficult to apply in current clinical practice, mostly because it doubles the evaluation time due to the necessary rest period between the two tests $(27,28)$. The use of this second supra-maximal constant-load test may further reduce the number of patients accessing to CPET, since access is already limited in many hospitals due to increasing numbers of patients being referred for testing.

\section{Incorporation of submaximal postoperative predictive factors}

The low reliability of the $\dot{\mathrm{V}} \mathrm{O}_{2 \text { peak }}$ as an evaluation of outcomes following pulmonary resection surgery has led some teams to evaluate other physiological indicators that are considered to be less affected by volition and duration of the exercise. Kasikcioglu et al. evaluated the oxygen uptake efficiency slope (OUES) during incremental CPET, calculated from the ratio of the $\dot{\mathrm{V}} \mathrm{O}_{2 \text { peak }}$ value and logarithmic equivalent of the ventilatory volume ( $\dot{\mathrm{V} E})$. They found almost identical predictive values for the risk of post-operative complications for the OUES and the $\dot{\mathrm{V}} \mathrm{O}_{2 \text { peak }}$ (29). More recently Yakal et al., showed that the OUES is significantly correlated with $\dot{\mathrm{V}}_{2 \text { peak }}$ and does not require the performance of maximal exercise (30). In parallel Torchio et al. and Brunelli et al. assessed ventilatory efficiency in patients with NSCLC who were eligible for surgery. They showed that the $\dot{\mathrm{V}} / \mathrm{VCO}_{2}$ slope, which is the linear regression of the ratio between the increase in minute ventilation $(\dot{V} E)$ and the expired carbon dioxide flow $\left(\dot{\mathrm{V}} \mathrm{CO}_{2}\right)$, was not only an accurate and independent predictive factor of mortality, but that it was also a more reliable predictor of postoperative complications than 
$\dot{\mathrm{V}} \mathrm{O}_{2 \text { peak }}(31-33)$. The $\dot{\mathrm{V}} / \dot{\mathrm{V}} \mathrm{CO}_{2}$ slope may represent a useful complementary indicator to stratify the postoperative complication risk independent of the $\dot{\mathrm{VO}}_{2 \text { peak }}$.

\section{Limitations}

This study has limitations that were inherent in its retrospective design. The first is that there may have been selection bias and due to the long period of data collection, some data may have been lost. Secondly, the comparison of data between patients who carried out different incremental protocols should be considered with caution because the study was not powered for these outcomes. Even if all tests were undertaken with the same team and the same equipment throughout in accordance with guidelines, which strengthens internal validity, the monocentric design limit the generalisability (external validity) of the study results. Despite these limitations, this work provides a concrete insight into the limitations of $\dot{\mathrm{V}}_{2 \text { peak }}$ in patients with NSCLC evaluated outside clinical trials. The difficulty in achieving the recommended duration for incremental CPET (or simply a sustained effort) has been reported by several teams, but, until now, there had been no objective report of the number of patients with NSCLC who failed to reach these maximum criteria.

Finally, as suggested by some authors "clinical $\dot{\mathrm{VO}}_{2 \text { peak }}$ is part of the deal" (27). It is possible that although the raw value of $\dot{\mathrm{V}}_{2}$ was underestimated, this peak value includes the painful or motivational component, and remains predictive of perioperative complications. Unmotivated or painful patients, even at CPET assessment, may have an impact on their post-operative recovery and outcomes. To date, this question remains unanswered and future works are needed to further refine our assessment methods in an increasingly large and severe population of candidates for pulmonary surgery.

\section{Conclusions}

This study showed that CPET prior to NSCLC surgery was mainly limited by ventilatory factors. About $30 \%$ of the patients in the present study did not achieve maximal effort during their CPET, therefore, the values of $\dot{\mathrm{V}} \mathrm{O}_{2 \text { peak }}$ possibly underestimated their cardio-respiratory fitness, leading to the potential overestimation of the risk of postsurgical complications. To overcome this issue, we suggest several strategies: (I) low-intensity incremental protocols (5 to 10 watts per minute) to increase the duration of the
CPET, (II) validation through a second evaluation, or (III) the incorporation of submaximal postoperative predictive factors. These strategies must however be validated in order to help to ensure that appropriate surgical and therapeutic decisions are made for patients with NSCLC.

\section{Acknowledgments}

We thank the Aide à Domicile aux Insuffisants Respiratoires (ADIR) Association for supporting this work, the Rouen University Hospital Physiology Department team for their help with data entry, and Johanna Robertson and Jennifer Dandrea-Palethorpe for language assistance and constructive criticism.

Funding: None.

\section{Footnote}

Reporting Checklist: The authors have completed the STROBE reporting checklist. Available at http://dx.doi. org/10.21037/jtd-20-1528

Peer Review File: Available at http://dx.doi.org/10.21037/jtd20-1528

Data Sharing Statement: Available at http://dx.doi. org/10.21037/jtd-20-1528

Conflicts of Interest: All authors have completed the ICMJE uniform disclosure form (available at http://dx.doi. org/10.21037/jtd-20-1528). The authors have no conflicts of interest to declare.

Ethical Statement: The authors are accountable for all aspects of the work in ensuring that questions related to the accuracy or integrity of any part of the work are appropriately investigated and resolved. The study was conducted in accordance with the Declaration of Helsinki (as revised in 2013). The study was approved by institutional Rouen University Hospital ethics committee ( $\left.{ }^{\circ} \mathrm{E} 2019-47\right)$ and individual consent for this retrospective analysis was waived.

Open Access Statement: This is an Open Access article distributed in accordance with the Creative Commons Attribution-NonCommercial-NoDerivs 4.0 International License (CC BY-NC-ND 4.0), which permits the noncommercial replication and distribution of the article with 
the strict proviso that no changes or edits are made and the original work is properly cited (including links to both the formal publication through the relevant DOI and the license). See: https://creativecommons.org/licenses/by-nc-nd/4.0/.

\section{References}

1. Bray F, Ferlay J, Soerjomataram I, et al. Global cancer statistics 2018: GLOBOCAN estimates of incidence and mortality worldwide for 36 cancers in 185 countries. CA Cancer J Clin 2018;68:394-424.

2. Duma N, Santana-Davila R, Molina JR. Non-Small Cell Lung Cancer: Epidemiology, Screening, Diagnosis, and Treatment. Mayo Clin Proc 2019;94:1623-40.

3. Howington JA, Blum MG, Chang AC, et al. Treatment of stage I and II non-small cell lung cancer: Diagnosis and management of lung cancer, 3rd ed: American College of Chest Physicians evidence-based clinical practice guidelines. Chest 2013;143:e278S-e313S.

4. Bott MJ, Patel AP, Crabtree TD, et al. Role for Surgical Resection in the Multidisciplinary Treatment of Stage IIIB Non-Small Cell Lung Cancer. Ann Thorac Surg 2015;99:1921-8.

5. Brunelli A, Charloux A, Bolliger CT, et al. ERS/ESTS clinical guidelines on fitness for radical therapy in lung cancer patients (surgery and chemo-radiotherapy). Eur Respir J 2009;34:17-41.

6. Brunelli A, Kim AW, Berger KI, et al. Physiologic evaluation of the patient with lung cancer being considered for resectional surgery: Diagnosis and management of lung cancer, 3rd ed: American College of Chest Physicians evidence-based clinical practice guidelines. Chest 2013;143:e166S-90S.

7. ATS/ACCP Statement on cardiopulmonary exercise testing. Am J Respir Crit Care Med 2003;167:211-77.

8. Benzo R, Kelley GA, Recchi L, et al. Complications of lung resection and exercise capacity: a meta-analysis. Respir Med 2007;101:1790-7.

9. Poole DC, Jones AM. Measurement of the maximum oxygen uptake Vo2max: Vo2peak is no longer acceptable. J Appl Physiol (1985) 2017;122:997-1002.

10. von Elm E, Altman DG, Egger M, et al. The Strengthening the Reporting of Observational Studies in Epidemiology (STROBE) statement: guidelines for reporting observational studies. PLoS Med 2007;4:e296.

11. Goldstraw P, Crowley J, Chansky K, et al. The IASLC Lung Cancer Staging Project: proposals for the revision of the TNM stage groupings in the forthcoming (seventh) edition of the TNM Classification of malignant tumours. J Thorac Oncol 2007;2:706-14.

12. Quanjer PH, Tammeling GJ, Cotes JE, et al. Lung volumes and forced ventilatory flows. Report Working Party Standardization of Lung Function Tests, European Community for Steel and Coal. Official Statement of the European Respiratory Society. Eur Respir J Suppl 1993;16:5-40.

13. Wasserman K, hansen J, Sue D, et al. Principles of Exercise Testing and Interpretation. 5th ed ed. Philadelphia, USA: Lippincott Williams \& Wilkins; 2011.

14. Tanaka H, Monahan KD, Seals DR. Age-predicted maximal heart rate revisited. J Am Coll Cardiol 2001;37:153-6.

15. Guazzi M, Arena R, Halle M, et al. 2016 Focused Update: Clinical Recommendations for Cardiopulmonary Exercise Testing Data Assessment in Specific Patient Populations. Circulation 2016;133:e694-711.

16. Wasserman K, Whipp BJ. Excercise physiology in health and disease. Am Rev Respir Dis 1975;112:219-49.

17. Pellegrino R, Viegi G, Brusasco V, et al. Interpretative strategies for lung function tests. Eur Respir J 2005;26:948-68.

18. Neder JA, Arbex FF, Alencar MC, et al. Exercise ventilatory inefficiency in mild to end-stage COPD. Eur Respir J 2015;45:377-87.

19. Granger CL, McDonald CF, Irving L, et al. Low physical activity levels and functional decline in individuals with lung cancer. Lung Cancer 2014;83:292-9.

20. Hulo S, Inamo J, Dehon A, et al. Chronotropic incompetence can limit exercise tolerance in COPD patients with lung hyperinflation. Int J Chron Obstruct Pulmon Dis 2016;11:2553-61.

21. Granger CL, McDonald CF, Berney S, et al. Exercise intervention to improve exercise capacity and health related quality of life for patients with Non-small cell lung cancer: a systematic review. Lung Cancer 2011;72:139-53.

22. Midgley AW, Bentley DJ, Luttikholt H, et al. Challenging a dogma of exercise physiology: does an incremental exercise test for valid VO 2 max determination really need to last between 8 and 12 minutes? Sports Med 2008;38:441-7.

23. Buchfuhrer MJ, Hansen JE, Robinson TE, et al. Optimizing the exercise protocol for cardiopulmonary assessment. J Appl Physiol Respir Environ Exerc Physiol 1983;55:1558-64.

24. Pessoa BV, Beltrame T, Di Lorenzo VA, et al. COPD patients' oxygen uptake and heart rate on-kinetics at cycleergometer: correlation with their predictors of severity. 
Braz J Phys Ther 2013;17:152-62.

25. Murias JM, Kowalchuk JM, Paterson DH. Speeding of VO2 kinetics with endurance training in old and young men is associated with improved matching of local O2 delivery to muscle O2 utilization. J Appl Physiol (1985) 2010;108:913-22.

26. Saynor ZL, Barker AR, Oades PJ, et al. Reproducibility of maximal cardiopulmonary exercise testing for young cystic fibrosis patients. J Cyst Fibros 2013;12:644-50.

27. van Breda E, Schoffelen PFM, Plasqui G. Clinical Vo2peak is "part of the deal". J Appl Physiol (1985) 2017;122:1370.

28. Cooper DM. Rethinking Vo2max: right problem, wrong solution (Letter to the Editor regarding Poole and Jones' "Measurement of the maximum oxygen uptake Vo2max: Vo2peak is no longer acceptable"). J Appl Physiol (1985) 2017;123:498.

29. Kasikcioglu E, Toker A, Tanju S, et al. Oxygen uptake kinetics during cardiopulmonary exercise testing and postoperative complications in patients with lung cancer.

Cite this article as: Gravier FE, Bonnevie T, Boujibar F, Médrinal C, Prieur G, Combret Y, Muir JF, Baste JM, Debeaumont D, Cuvelier A. Cardiopulmonary exercise testing in patients with non-small cell lung cancer: trust the $\dot{\mathrm{V}}_{2 \text { peak }}$ ? J Thorac Dis 2020;12(10):5313-5323. doi: 10.21037/jtd-20-1528
Lung Cancer 2009;66:85-8.

30. Yakal S, Sofyali S, Ozkan B, et al. Oxygen Uptake Efficiency Slope and Prediction of Post-operative Morbidity and Mortality in Patients with Lung Cancer. Lung 2018;196:255-62.

31. Torchio R, Guglielmo M, Giardino R, et al. Exercise ventilatory inefficiency and mortality in patients with chronic obstructive pulmonary disease undergoing surgery for non-small-cell lung cancer. Eur J Cardiothorac Surg 2010;38:14-9.

32. Brunelli A, Belardinelli R, Pompili C, et al. Minute ventilation-to-carbon dioxide output (VE/VCO2) slope is the strongest predictor of respiratory complications and death after pulmonary resection. Ann Thorac Surg 2012;93:1802-6.

33. Torchio R, Mazzucco A, Guglielmo M, et al. Minute ventilation to carbon dioxide output $\left(\mathrm{V}^{\prime} \mathrm{E} / \mathrm{V}^{\prime} \mathrm{CO} 2\right.$ slope $)$ is the strongest death predictor before larger lung resections. Monaldi Arch Chest Dis 2017;87:817. 
Table S1 Comorbidities and medications

\begin{tabular}{|c|c|}
\hline Variable & $n(\%)$ \\
\hline \multicolumn{2}{|l|}{ Diagnosed/treated comorbidities } \\
\hline \multicolumn{2}{|l|}{ Cardiovascular } \\
\hline Arterial hypertension & $97(47.8)$ \\
\hline Arteriopathy & $42(20.7)$ \\
\hline Cardiopathies & $25(12.3)$ \\
\hline Atrial fibrillation & $12(5.9)$ \\
\hline Stroke & $9(4.4)$ \\
\hline Vein thrombosis & $6(3.0)$ \\
\hline Pulmonary embolism & $4(2.0)$ \\
\hline \multicolumn{2}{|l|}{ Respiratory } \\
\hline Chronic obstructive pulmonary disease/emphysema & $109(53.7)$ \\
\hline Apnoea & $14(6.9)$ \\
\hline Asbestosis & $6(3.0)$ \\
\hline Tuberculosis & $4(2.0)$ \\
\hline Asthma & $3(1.5)$ \\
\hline Aspergillosis & $3(1.5)$ \\
\hline \multicolumn{2}{|l|}{ Digestive/metabolic/endocrine } \\
\hline Dyslipidaemia & $63(31.0)$ \\
\hline Diabetes & $35(17.3)$ \\
\hline Alcoholism & $22(10.8)$ \\
\hline Hypothyroidy & $14(6.9)$ \\
\hline Peptic ulcer & $11(5.4)$ \\
\hline Chronic pancreatitis & $4(2.0)$ \\
\hline Renal failure & $3(1.5)$ \\
\hline \multicolumn{2}{|l|}{ Orthopaedic and rheumatology } \\
\hline Hip/knee prosthesis & $14(6.9)$ \\
\hline Osteoarthritis & $11(5.4)$ \\
\hline Chronic low back pain & $10(4.9)$ \\
\hline Spinal hernia & $8(3.9)$ \\
\hline Gouty arthritis & $6(3.0)$ \\
\hline Rheumatoid arthritis & $4(2.0)$ \\
\hline Osteoporosis & $3(1.5)$ \\
\hline \multicolumn{2}{|l|}{ Oncologic } \\
\hline Pulmonary & $12(5.9)$ \\
\hline Prostate & $12(5.9)$ \\
\hline Gynaecological & $3(1.5)$ \\
\hline Colorectal & $3(1.5)$ \\
\hline Otorhinolaryngologic & $2(1.0)$ \\
\hline Anxio-depressive syndrome & $19(9.4)$ \\
\hline Per patient median (IQR) & $3(2-4)$ \\
\hline \multicolumn{2}{|l|}{ Medications } \\
\hline Antihypertensive & $96(47.3)$ \\
\hline Long-acting bronchodilators & $94(46.3)$ \\
\hline Antiplatelet agent & $86(42.4)$ \\
\hline Lipid-lowering & $70(34.5)$ \\
\hline Antiarrhythmic & $40(19.7)$ \\
\hline Of which beta-blocker & $32(15.8)$ \\
\hline Inhaled corticosteroids & $38(18.7)$ \\
\hline Anxiolytic & $35(17.2)$ \\
\hline Gastric antisecretory & $34(16.7)$ \\
\hline Short-acting bronchodilators & $30(14.8)$ \\
\hline Opioid analgesic & $25(12.3)$ \\
\hline Oral anti-diabetic & $24(11.8)$ \\
\hline Paracetamol & $23(11.3)$ \\
\hline Antidepressant & $21(10.3)$ \\
\hline Anticoagulant & $18(8.9)$ \\
\hline Vitamins & $16(2.5)$ \\
\hline Thyroid hormone & $15(7.4)$ \\
\hline Insulin & $14(6.9)$ \\
\hline Diuretic & $14(6.9)$ \\
\hline Hypnotics & $13(6.4)$ \\
\hline Anti-gout & $7(3.4)$ \\
\hline Nicotine substitutes & $6(3.0)$ \\
\hline Alpha blockers & $6(3.0)$ \\
\hline Nocturnal oxygen therapy and/or ventilation & $5(2.5)$ \\
\hline Antifungal & $5(2.5)$ \\
\hline Oral corticosteroids & $5(2.5)$ \\
\hline Anti-epileptic & $4(2.0)$ \\
\hline Immunosuppressant & $4(2.0)$ \\
\hline Antihistamine & $3(1.5)$ \\
\hline Per patient median (IQR) & $4(2-6)$ \\
\hline
\end{tabular}

